\title{
A GRAPHICAL SOLUTION OF EMPIRICAL RELATIONS OF ONE INDEPENDENT VARIABLE IN A FUNCTION CON TAINING FOUR UNDETERMINED CONSTANTS
}

\author{
By WaLTER BaRTKY, \\ - Lewis Institute, Chicago.
}

Empirical relations are approximate relations between quantities obtained from experimental values of the quantities involved. This article will be devoted to the consideration of empirical equations of one independent variable in a function having four constants. A knowledge of elementary graphs is, of course, necessary. The equation of a straight line on rectangular coordinates can be expressed in the general form: $y=m x+b$, where $x$ and $y$ are the variables, $b$ the intercept on the $y$-axis, and $m$ the slope of the line. If points representing the values of two related quantities are plotted on rectangular coordinates and lie approximately on the same straight line, the empirical relation is of the form, $y=m x+b$, where $x$ and $y$ represent the quantities, while $m$ and $b$ are constants that are easily determined from the position of the line. Other empirical relations of one independent variable in a function having two constants can be reduced to the straight line form by letting $x$ and $y$ equal certain simple functions of the quantities involved.

Now consider an empirical equation of the form: $s=A t^{3}+B t^{2}+$ $C t+D . \quad A, B, C$, and $D$ are constants to be determined, and $s$ and $t$ are variables. Certain sets of values of $s$ and $t$ are obtained experimentally. It is desired to determine the constants of an empirical equation of this form for these values. Let $s_{1}$ and $t_{1}$ represent one pair of values of $s$ and $t$. On rectangular coordinates where $O X$ and $O Y$ are the axes, the line is plotted,

$$
y=s_{1} \text {. }
$$

Suppose this line is cut by a line the equation of which is

$$
y=m x+b \text {. }
$$

At the intersection of the two lines (1) and (2),

$$
s_{1}=m x+b \text { or } x=\left(s_{1}-b\right) / m \text {. }
$$

On another system of coordinates where $O X^{\prime}$ and $O Y^{\prime}$ are the axes the line is plotted:

$$
t_{1}=\left(s_{1}\right)^{2} x^{\prime}+y^{\prime} \text {. }
$$

Suppose this line is cut by a line the equation of which is

$$
y^{\prime}=m^{\prime} x^{\prime}+b^{\prime}
$$

At the intersection of the two lines (4) and (5)

$$
t_{1}=\left(s_{1}\right)^{2} x^{\prime}+m^{\prime} x^{\prime}+b^{\prime} .
$$

Now let the $x$ of (3) be identical with the $x^{\prime}$ of (6), then substituting since $x=x^{\prime}=\left(s_{1}-b\right) / m$, 


$$
t_{1}=\left[\left(s_{1}\right)^{3}\right] / \mathrm{m}-\left[b\left(s_{1}\right)^{2}\right] / m+\left[m^{\prime}\left(s_{1}\right)\right] / m-\left(b m^{\prime}\right) / m+b^{\prime} .
$$

If for every set of values of $s$ and $t$ the same two sets of lines are plotted, namely:

$$
\begin{aligned}
& y=s, \\
& t=s^{2} x^{\prime}+y^{\prime},
\end{aligned}
$$

and if each set of lines, (8) and (9) is cut by a line of form respectively,

$$
\begin{aligned}
& y=m x+b, \\
& y^{\prime}=m^{\prime} x^{\prime}+b^{\prime},
\end{aligned}
$$

so that the values of $x$ and $x^{\prime}$ for each corresponding pair of intersection points on lines (8) and (9) are approximately the same, then an approximate relation between $s$ and $t$ is,

$$
t=\left(s^{3}\right) / m-\left(b s^{2}\right) / m+\left(m^{\prime} s\right) / m-\left(b m^{\prime}\right) / m+b^{\prime} .
$$

This is the same form as,

$$
t=A s^{3}+B s^{2}+C s+D
$$

In figure 1 a relation of this form is found between the following values of $s$ and $t$ :

$\begin{array}{rrrrr}s= & 1 & 2 & 3 & 4 \\ t= & 0 & .5 & 2 & 3 \\ & 5 & 3.4 & 5 & 27\end{array}$

For each of these four values four straight lines are plotted on $x$ - $y$-axes from the relation, $x=s$, namely:
(1). $\quad x=0$;
(2). $x=.5$;
(3). $x=2$;
(4). $x=3$.

Also on $x^{\prime}-y^{\prime}$-axes four lines are plotted from relation. $t=s^{2} x^{\prime}+y^{\prime}$, namely:
$\left(1^{\prime}\right) .5=y^{\prime}$.
$\left(2^{\prime}\right) .3 .4=.25 x^{\prime}+y^{\prime}$.
$\left(3^{\prime}\right) .5=4 x^{\prime}+y^{\prime}$. (4'). $27=9 x^{\prime}+y^{\prime}$.

The first and second sets of lines are cut, so that $x$ and $x^{\prime}$ of the intersection points is the same for corresponding pairs of lines by the lines,

$$
\begin{aligned}
& y=.5 x+1.5 \\
& y^{\prime}=-x^{\prime}+2 .
\end{aligned}
$$

Hence $m=.5, b=1.5, m^{\prime}=-1, b^{\prime}=2$.

Equation (12) becomes after substitution, $t=2 s^{3}-3 s^{2}-2 s+5$.

In figure 1 it is readily seen that the lines (1), (2), (3), and (4) are parallel, likewise the lines $\mathrm{AA}^{\prime}, \mathrm{BB}^{\prime}, \mathrm{CC}^{\prime}$, and $\mathrm{DD}^{\prime}$. Hence it follows by geometry that the line $y^{\prime}=m^{\prime} x^{\prime}+b^{\prime}$ must cut the lines plotted on the $x^{\prime}-y^{\prime}$-axes at distances, $\mathrm{A}^{\prime} \mathrm{B}^{\prime}$, $\mathbf{B}^{\prime} \mathrm{C}^{\prime}$, and $\mathrm{C}^{\prime} \mathrm{D}^{\prime}$, proportional to the distances between the lines (1) and (2), (2) and (3), (3) and (4). This principle is used in figure 2, to determine the position of the line: $y^{\prime}=m^{\prime} x^{\prime}+b^{\prime}$. The same type of relation is found for the following values of $s$ and $t$. 


\begin{tabular}{|c|c|c|c|c|c|c|}
\hline 1 & 2 & 3 & 4 & 5 & 6 & 7 \\
\hline $\begin{array}{l}=\quad 1.0 \\
\text { Gravity.) }\end{array}$ & 1.1 & 1.2 & 1.3 & 1.4 & 1.5 & 1.6 \\
\hline $\begin{array}{c}=\quad 0.0 \\
\text { Bs Baumê.) }\end{array}$ & 13.2 & 24.2 & 33.5 & 41.5 & 48.4 & 54.4 \\
\hline
\end{tabular}

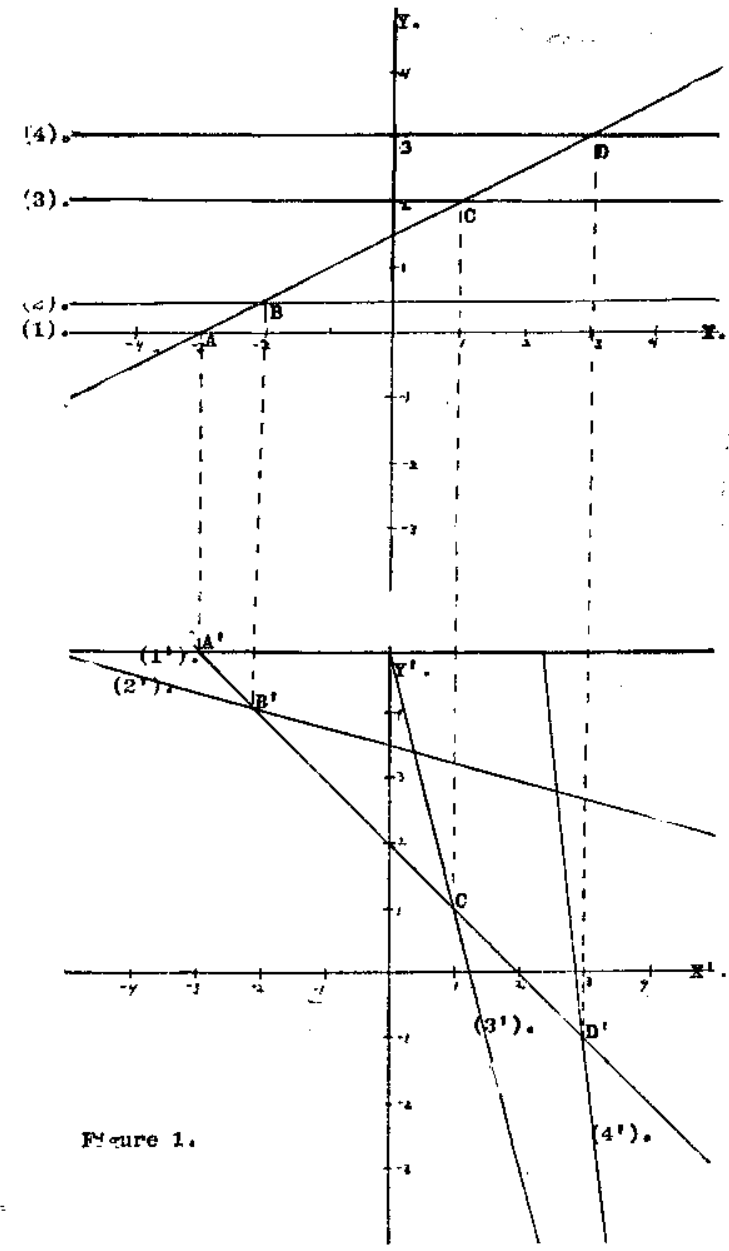

As in figure 1, two sets of lines are plotted. In addition a set of parallel lines, $\left(1^{\prime \prime}\right),\left(2^{\prime \prime}\right),\left(3^{\prime \prime}\right)$, etc., is ruled on transparent paper at distances proportional to the distances between the lines (1), (2), (3), etc. These parallel lines on transparent paper are then placed on the lines $\left(1^{\prime}\right),\left(2^{\prime}\right),\left(3^{\prime}\right)$, etc., and moved about until the intersections of each pair of lines, $\left(1^{\prime}\right)$ and $\left(1^{\prime \prime}\right),\left(2^{\prime}\right)$ and $\left(2^{\prime \prime}\right),\left(3^{\prime}\right)$ and $\left(3^{\prime \prime}\right)$, etc., are approximately in the same straight line. 
This line of intersections is the required line $y^{\prime}=m^{\prime} x^{\prime}+b^{\prime}$ since the intersections of the line on the lines $\left(1^{\prime}\right),\left(2^{\prime}\right),\left(3^{\prime}\right)$, etc., are at distances proportional to the distances between the parallel lines (1), (2), (3), etc. The position of the line, $y=m x+b$ is then easily determined since the value of $x$ and $x^{\prime}$ for corresponding intersection points is the same. In this example different

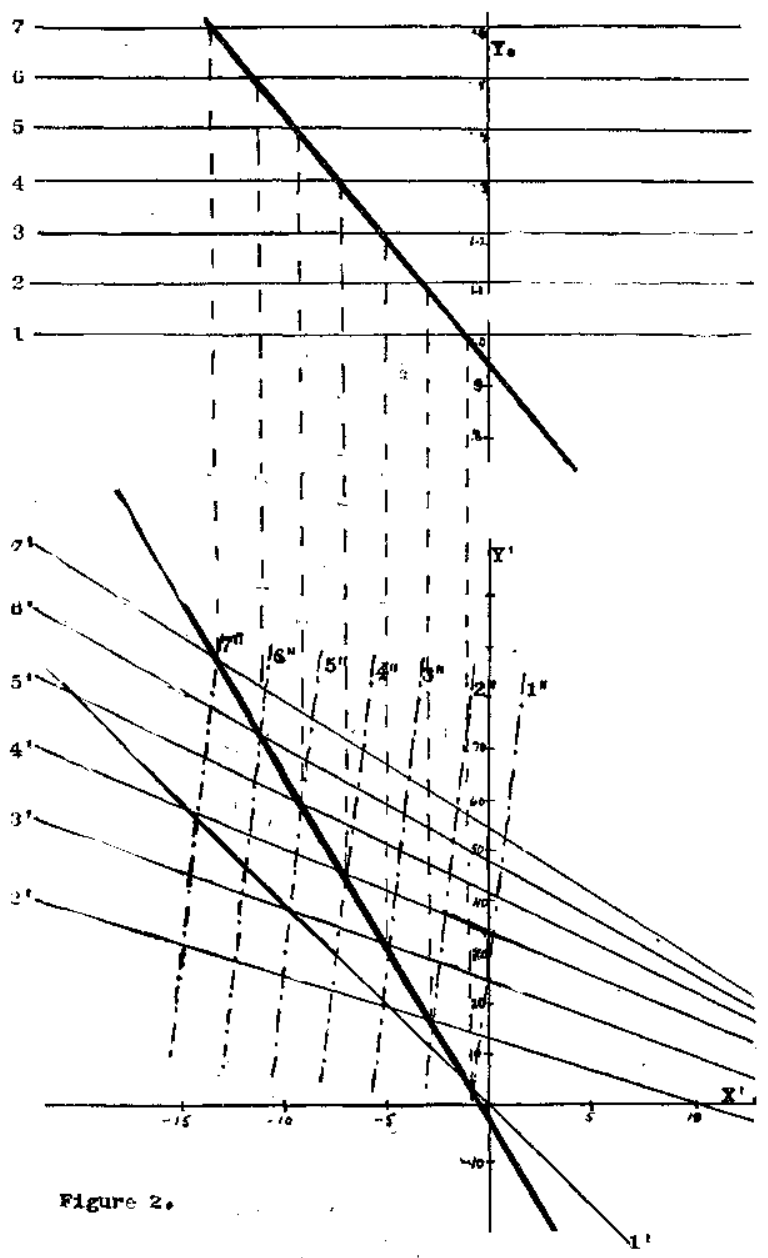

units are used on the $y$-axis and the $y^{\prime}$-axis, but the $x$-axis and the $x^{\prime}$-axis have the same units. The two intersecting lines are,

$$
\begin{aligned}
& y=-.048 x+.95 \\
& y^{\prime}=-6.75 x^{\prime}-4 .
\end{aligned}
$$

Hence, $m=-.048, b=+.95, m^{\prime}=-6.75, b^{\prime}=-4$. 
Equation (12) becomes after substitution,

$$
t=-20.8 s^{3}+19.8 s^{2}+140 s-139 \text {. }
$$

Now consider the empirical equation,

$$
t=A s^{C}+B s^{D},
$$

in which $s$ and $t$ are the variables, and $A, B, C$, and $D$ are the constants to be determined. Practically the same method is employed. On $x$-y-axes and on $x^{\prime}-y^{\prime}$-axes the following pairs of curves are plotted for each set of values of $s$ and $t$,

$$
s=e^{y}
$$

$\log t=\log \left(e^{x^{\prime}}+1\right)+y^{\prime}$.

( $e$ the base of the natural logarithms or any other base may be used.)

As before the curves are cut, so that the value of $x$ and $x^{\prime}$ is the same for corresponding intersection points, by the lines,

$$
\begin{aligned}
y & =m x+b, \\
y^{\prime} & =m^{\prime} x^{\prime}+b^{\prime} .
\end{aligned}
$$

From (2) and (4) $\log t=\log \left(e^{x^{\prime}}+1\right)+m^{\prime} x^{\prime}+b^{\prime}$. Since $x=x^{\prime}$ from (6) and (7) is obtained,

$$
\begin{aligned}
\log t & =\log \left(e^{1 / m \log s-b / m}+1\right) \\
& +m^{\prime}(1 / m \log s-b / m)+b^{\prime} .
\end{aligned}
$$

Simplifying,

$$
t=e^{\left(b^{\prime} m-b-b m^{\prime}\right) / m} s^{\left(1+m^{\prime}\right) / m}+e^{\left(b^{\prime} m-b m^{\prime}\right) / m} s^{m^{\prime} / m} .
$$

This is the same form as,

$$
t=A s^{C}+B s^{D}
$$

and $\quad C=\left(1+m^{\prime}\right) / \mathrm{m}, D=m^{\prime} / m$,

$$
\begin{aligned}
& A=\text { antilog }\left[b^{\prime}-b / m\left(1+m^{\prime}\right)\right]=\text { antilog }\left[b^{\prime}-b C\right], \\
& B=\text { antilog }\left[b^{\prime}-m^{\prime} / m\right]=\text { antilog }\left[b^{\prime}-b D\right] .
\end{aligned}
$$

In figure 3 an empirical relation of this type is obtained for the following values of $s$ and $t$ :

$$
\begin{array}{llllll}
s= & 1 & 2 & 3 & 4 & 5 \\
t= & \multicolumn{1}{l}{\begin{array}{l}
1 \\
t=176
\end{array}} & .641 & 4 & 10 & 20 \\
& & & 2.61 & 21.47 & 101.3
\end{array}
$$

For the above values from the equation: $s=e^{y}$ the curves obtained in figure 3 are: (1), (2), (3), (4), and (5). Common logarithms are used and $e$ is replaced by 10 . These curves are parallel. Hence the same set of curves or parallels are plotted on transparent paper to aid in the solution, as explained in the example of figure 2, namely: $\left(1^{\prime \prime}\right),\left(2^{\prime \prime}\right),\left(3^{\prime \prime}\right),\left(4^{\prime \prime}\right)$, and $\left(5^{\prime \prime}\right)$. From the equation $\log t=\log \left(e^{x^{\prime}}+1\right)+y^{\prime}$, the curves obtained are: $\left(1^{\prime}\right),\left(2^{\prime}\right),\left(3^{\prime}\right),\left(4^{\prime}\right)$, and $\left(5^{\prime}\right)$. In plotting these curves the 
curve for one value of $t$ is obtained. Suppose $t=1$. Then $-y^{\prime}=\log \left(10^{x \prime}+1\right)$. The curve for any other value of $t$ is then easily obtained by lowering the $x^{\prime}$-axis. The lines that intersect these two sets of eurves making $x=x^{\prime}$ are:

$$
\begin{aligned}
& y=x+.4, \\
& y^{\prime}=1.5 x-.3 .
\end{aligned}
$$

Hence $m=1, b=.4, m^{\prime}=1.5, b^{\prime}=-.3$,

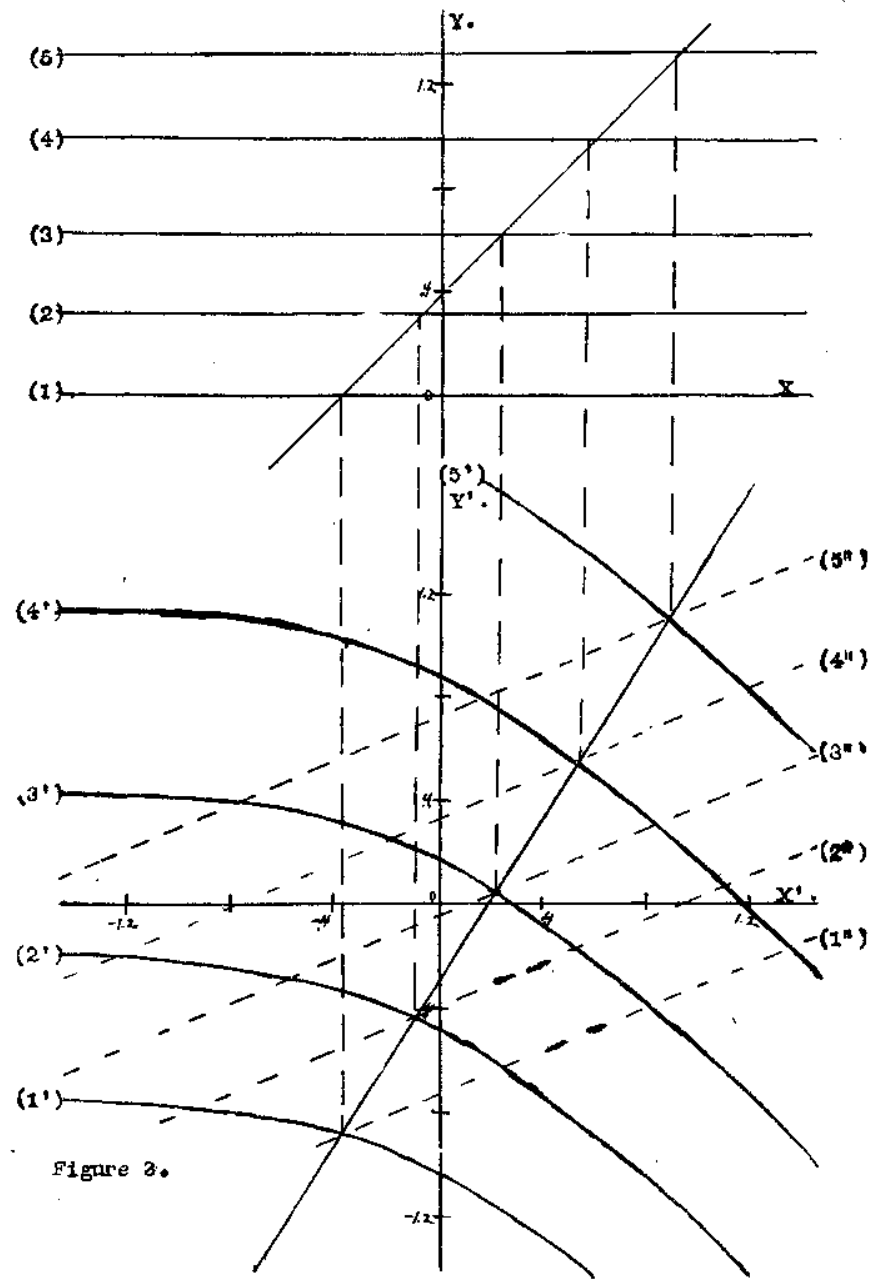

$$
C=2.5, D=1.5, A=\text { antilog }-1.3=.05, B=
$$
antilog $-.9=.126$, and $t=A s^{C}+B s^{D}$ becomes $t=.05 s^{2.5}$ $+.126 s^{1.5}$.

The table is an aid in solving empirical relations of four con- 
stants by this method. Different types of empirical equations are listed under equation. In these equations $s$ and $t$ are the variables. $A, B, C$, and $D$ are the four constants that are to be determined. $n, p, q, r$, are known constants, the value zero included. The next two columns called $x$-y-axes and $x^{\prime}-y^{\prime}$-axes give the curves that are plotted on an $x-y$-axes and an $x^{\prime}-y^{\prime}$-axes for each set of values of $s$ and $t$. The columns headed $A, B, C$, and $D$ give the values of these constants in terms of the slope and $y$-intercept of the straight lines that eut the two sets of

TABLE. ${ }^{\mathrm{I}}$

\begin{tabular}{|c|c|c|}
\hline Equation & $x-y$-axes & $x^{\prime}-y^{\prime}-a x e s$ \\
\hline $\begin{array}{l}t=A s^{3}+B s^{2}+C s+D \\
t=A s^{3 \mathrm{n}}+B s^{2 \mathrm{n}}+C s^{\mathrm{n}}+D \\
t=A s^{3 \mathrm{n}+\mathrm{r}}+B s^{2 \mathrm{n}}+\mathrm{r}+C s^{\mathrm{n}}+\mathrm{r}+D s^{\mathrm{r}}\end{array}$ & $\left\{\begin{array}{l}y=s \\
y=s^{12} \\
y=s^{n}\end{array}\right.$ & $\begin{array}{l}t=s^{2} x^{\prime}+y^{\prime} \\
t=s^{2 n} x^{\prime}+y^{\prime} \\
(l-q) / s \quad s^{2 n} x^{\prime}+y^{\prime}\end{array}$ \\
\hline $\begin{array}{l}t=A s^{\mathrm{a}+\mathrm{r}}+B s^{\mathrm{r}}+C s^{\mathrm{n}+\mathrm{p}}+D s^{\mathrm{p}}+q \\
t=(A s+B)^{\mathrm{n}}(C s+D)^{\mathrm{r}}+q \\
t=(A s+B)^{\mathrm{n}}+(C s+D)^{\mathrm{r}}+q \\
t=\sin (A s+B)+\cos (C s+D) \\
t=F(A s+B, C s+D) \\
f(t, s)=F(t, s, q, A s+B, C s+D) \\
t=A s C+B s D \\
t=A s^{C}-B s^{D} D \\
t=A(s+n) C+B(s+n)^{D}+q\end{array}$ & $\begin{array}{l}y=s^{\mathbf{n}} \\
y=s \\
y=s \\
y=s \\
y=s \\
y=s \\
y=\log s \\
y=\log s \\
y=\log (s+n)\end{array}$ & $\begin{array}{l}t=s^{\mathrm{r}} x^{\prime}+s^{\mathrm{p}} y^{\prime}+q \\
i=\left(x^{\prime}\right)^{\mathrm{n}}\left(y^{\prime}\right)^{\mathrm{r}}+q \\
t=\left(x^{\prime}\right)^{\mathrm{n}}+\left(y^{\prime}\right)^{\mathrm{r}}+q \\
t=\sin x^{\prime}+\cos y^{\prime} \\
t=F\left(x^{\prime}, y^{\prime}\right) \\
f(t, s)=F^{\prime}\left(t, s, q, x^{\prime}, y^{\prime}\right) \\
\log t=\log \left(e^{\mathrm{x}^{\prime}}+1\right)+y^{\prime} \\
\log t=\log \left(e^{\mathrm{x}^{\prime}}-1\right)+y^{\prime} \\
\log (t-q)=\log \left(e^{\mathrm{x}^{\prime}}+1\right)\end{array}$ \\
\hline$t=A(s+n)^{C}-B(s+n)^{D}+q$ & $y=\log (s+n)$ & $\log (t-q)=\log \left(e^{\mathrm{x}^{\prime}}-1\right)$ \\
\hline $\begin{array}{l}t=e^{A s+B}+e^{C s+D} \\
t=e^{A s+B}-e^{C s+D} \\
t=(A s+B) C s+D\end{array}$ & $\begin{array}{l}y=s \\
y=s \\
y=s\end{array}$ & $\begin{array}{l}t=e^{x^{\prime}}+e^{y^{\prime}} \\
t=e^{x^{\prime}}+e^{y^{\prime}} \\
t=x^{\prime} y^{\prime}\end{array}$ \\
\hline
\end{tabular}

\begin{tabular}{|c|c|c|c|}
\hline$A$ & $B$ & $C$ & $D$ \\
\hline$+1 / / m$ & $-b / m$ & $m^{\prime} / m$ & $\left(-b m^{\prime} /, m\right)+b^{\prime}$ \\
\hline$"$ & " & $"$ & $"$ \\
\hline$"$ & $"$ & " & $"$ \\
\hline$"$ & $"$ & ", & $"$ \\
\hline$"$ & $"$ & ", & " \\
\hline$"$ & $"$ & $"$ & $"$ \\
\hline$"$ & ", & ", & $"$ \\
\hline " & " & " & "' \\
\hline $\operatorname{antilog}\left[b^{\prime}-b / m\left(1+m^{\prime}\right)\right]$ & antilog $\left[b^{\prime},-m^{\prime} / m\right]$ & $\left(1+m_{, \prime}^{\prime}\right) / m$ & $m^{\prime} / m$ \\
\hline$"$ & , & $"$ & ", \\
\hline ", & "' & $"$ & " \\
\hline$+1 /, m$ & $-b / m$ & $m^{\prime} / m$ & $\left(-b m^{\prime} /, m\right)+b^{\prime}$ \\
\hline$"$ & $"$ & $"$ & $"$ \\
\hline
\end{tabular}

In any of the above examples $s$ or $t$ may be replaced by any function of $s$ and $t$.

For example, s or $t$ may be replaced by $s^{2}, s t, s+q, t+q, \sin s, \log t, l^{t}$, $t \log s$, etc.

\footnotetext{
1The second half of this table is a continuation, line for line, of the firat half.
} 
curves so that $x$ and $x^{\prime}$ are equal. If one of the sets of curves is a series of parallel lines then transparent paper with these parallel lines may be used in determining the position of the intersecting lines, $y=m x+b$, and $y^{\prime}=m^{\prime} x^{\prime}+b^{\prime}$.

Of course, this method is not as accurate as other methods involving advanced mathematics. It has its use in determining empirical equations of these types with a fair degree of accuracy and a minimum of calculations. Furthermore, in using this method there is very little restriction in selecting values of the quantities, four sets of values being sufficient for a solution.

\section{RADIAL VELOCITY CATALOGUE.}

A "First Catalogue of Radial Velocities" by J. Voute, of Java, Dutch East Indies, has just been issued. In this publication the author has compiled a list of the radial velocities of over 1900 stars and of 148 nebulae and elusters, thus bringing together material scattered through various publications. A catalogue of this nature will be of value for various statistical studies as it contains not only the radial velocity with the name of the observatory making the observations but also the magnitude, proper motion, type of spectrum, parallax when known, and the galactic latitude and longitude for each objectlisted.-[Popular Astronomy.

\section{NEED TO CHECK CONSUMPTION AS WELL AS TO INCREASE PRODUCTION OF OIL.}

The first thought in either a national or a world program for oil is to stimulate production; "more oil needed" deseribed the symptom felt by every nation, and new and larger supplies of oil is the remedy sought. Taking the long view as well as the broad view, however, we are forced to admit the equal need of checking consumption. A world policy, if it is to safeguard the future, must draw up a program that will favor thrift in the use of the oil eurrently produced, and in that program also there must be a joining of the nations in continued effort for the common good. When the world runs short of oil all nations will suffer, regardless of the geographic location of the remaining wells. Ameriea has led in teaching the world to use petroleum, whether in lamp or automobile or tractor, and it should be America's special duty to teach the world to use petroleum most efficiently.

The oil problem can be solved only through a keener realization of the world's future needs and a stronger determination to serve future interests. Any taking over of the rules of war into the economic competition for new supplies of oil or for markets for oil products will waste a limited resource as well as threaten world peace. If a high executive of one of the largest steel companies can address the American Iron and Steel Institute on the Golden Rule in Business the same thought may well be given this wider application before the American Petroleum Institute. Diplomacy--whethor old world or new world-can offer no better guide in these questions of world economies than is found in the Golden Rule. No other theory of international conduct is so worthy of a democratic nation or can be so easily applied to practical issues, and its application to oil is absolutely necessary if we are to make the world's oil serve the greatest number of generations.-[U. S. Geol. Survey. 